\title{
Words, deeds and interpretations
}

\author{
CMAJ Podcasts: Article reading at https://soundcloud.com/cmajpodcasts/160498-enc
}

I am an old psychiatrist. In my day (the late 1950s), we were taught to mainly listen to patients and only occasionally to throw in wise words. Despite this teaching, we occasionally "acted out," did instead of talked. Because actions can be interpreted in many ways, even more so than words, acting out inevitably led to misunderstanding between patient and doctor. For instance, one of my teachers told me that he always made a point of watering his plants with patients in the room so that they could make the connection - "he takes good care of his plants so he will take good care of me." However, one of his patients told me that she considered this incredibly rude: neglecting her for a good 10 minutes of her time while he made the rounds of his planted pots.

Another of my teachers, whenever patients complained, would ask them to take off their shoes so that he could "step into them." This, he said, made patients feel that he was sympathetic to their woes. However, a patient of his told me that she thought he was making fun of her. That's the problem with thinking you know what people mean by what they do.

Once I gave one of my patients, who was a single mother with a small child, a boxful of toys that my grandchildren had outgrown. I thought she would be overjoyed. But, somehow, one of my old discarded shoes had found its way into the box. Giving someone an old shoe was bad news in Korea. It means you want the person to walk away from you; to get lost. My patient was of Korean descent, and she never trusted me again, despite my repeated explanations that the shoe was never intended to be there.

Patients act out too, in incomprehensible ways. When I was a young

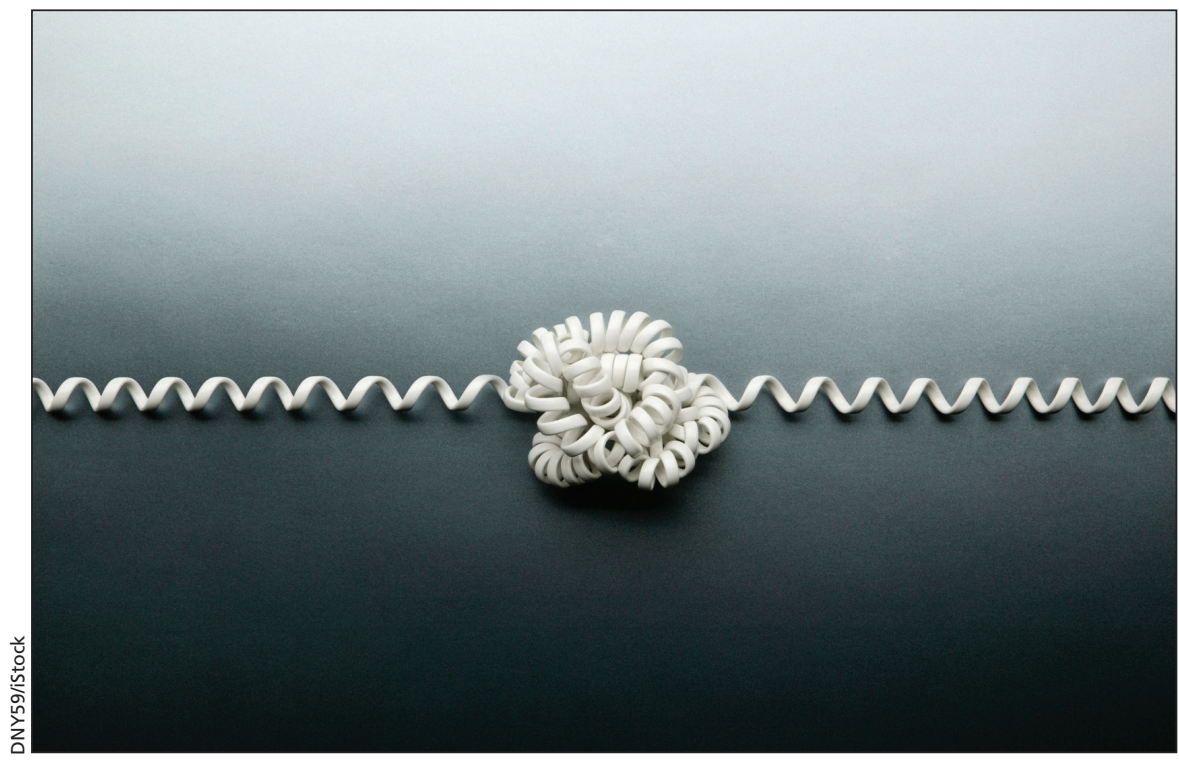

resident and visibly pregnant, one of my patients marched into my office and punched me in the nose. My feelings were terribly hurt, as was my nose, which hasn't been the same since. My supervisor was not sympathetic. He said, "She vomited outside your office door the day before, so you should have known she was trying to tell you something." What was she trying to tell me? That she couldn't stand my guts? The patient told me later that the vomiting and the punching was to express her identification with me, because she had felt both nauseous and as if someone had punched her in the nose during an unwelcome pregnancy. I don't know that she told me the full story. She probably didn't know herself what the full story was.

That was the only time I have been hit by a patient, but I have been threatened many times. One patient once brought a long butcher knife to her appointment and said she was very angry and meant to get back at me for something I had said. At my wits' end,
I asked her if it would be okay to call in an arbiter, Mischa Rejskind, who was the psychiatrist next door. Fortunately, she agreed to this and, at his instigation, we made an odd compromise. I would keep the knife in a drawer in my office. That way, whenever she came, she would still have the option of using it, so she felt no pressure to do it today. I kept that knife in my drawer, as promised, until I moved out of the office, and the patient never again expressed the desire to use it.

I learned a lot from Mischa and his paradoxical ways because the wall was thin between our offices, and he had a habit of shouting at his patients. He was very directive and would shout things like "Forget him!", "Move on!", "Do it, you'll like it." I thought his patients must be afraid of him; but, after his death, I inherited some of his patients and at least one thought he was in love with her because their sessions were like "lovers' spats."

During the period when my office was next door to Mischa's, we shared a 
small waiting room for our patients. One of my patients decided to take off all her clothes in the waiting room and paint her body red, white and yellow. Mischa knocked on my door and told me I had to do something about my patient, "but don't laugh," he said. I ended my current patient's session early and asked my patient in the waiting room to come in. She wasted no time in telling me that, since I had laughed at her the last time I saw her, she had dressed up as a clown for my benefit. Mischa had been right as usual. My laughter (which served to camouflage many unacknowledged emotions) always got me into trouble; another example of behaviour being easily misunderstood.

Of course, the patient I had let go early wasn't happy. She banged up the coat stand in the hallway, scattering coat hangers all over the corridor. This was to tell me I had treated her like an old coat. I didn't laugh. I told her she would have to pay for the damage and, Mischa, coming out into the hallway to investigate the noise, approved.
Words, of course, can be misunderstood too. One patient was convinced that I had told him I loved him when he called me one night at home, having somehow unearthed my home number. I think I told him on the phone "Call me at the office." Maybe the "off" in "office" over the phone sounded like love. I could not convince him of his mistake, and his wife was prepared to sue me for alienation of affection. I had to call in the couple's children to straighten out this muddle.

Another patient insisted that I was making lewd remarks to him day in and day out. He left repeated messages telling me to stop and desist or else. I became very scared of his threats and contacted the hospital lawyer, who asked me if I would be equally scared if the caller was a woman. I said, no, because men are stronger and more aggressive, so they scare me more. The lawyer said I was being sexist and recommended I sort it out myself.

It was around that time that I decided to restrict my practice to women. People thought I was scared of violence, which was true. I no longer would have to see that particular patient, which was a big relief, but it was more complicated than that. There were selfish reasons for my decision (it made my life easier), altruistic reasons (it made my patients' lives easier), noble reasons and also shameful reasons, both acknowledged and unacknowledged. Actions can be as much a mystery to the actor, I have come to believe, as they are to the observer.

\section{Mary V. Seeman MD}

Department of Psychiatry, University of Toronto, Toronto, Ont.

This article has been peer reviewed.

These events are true but happened decades ago. Patient names have been omitted.

CMAJ 2016. DOI:10.1503/cmaj.160498

"Wherever the art of medicine is loved, there is also a love of Humanities." - Hippocrates 